\title{
Jogo digital AcessaExata "Ciências Exatas Interdisciplinar - integrando linguagens da ciência com a acessibilidade para surdos"
}

\author{
Juego digital AcessaExata "Ciencias exactas interdisciplinares - \\ integrando lenguajes de la ciencia con accesibilidad para sordos"
}

\author{
Digital game AcessaExata "Exact Sciences Interdisciplinary - integrating \\ languages of science with accessibility for the deaf"
}

\author{
Wesley Alberto de Farias ${ }^{1}$ \\ Willian Rubira da Silva ${ }^{2}$ \\ Valmir Heckler ${ }^{3}$
}

\begin{abstract}
Resumo
O curso de Física apresenta um alto índice de desistência na Universidade Federal do Rio Grande - FURG, em especial no primeiro ano desse curso. $\mathrm{O}$ problema se agrava ainda mais no que tange as questões de acessibilidade, implicando que ações com práticas inclusivas das pessoas com deficiência auditiva devem ser exploradas nas Universidades. Visto isso, decidimos buscar outra estratégia, nesse caso, decidimos desenvolver um jogo educativo com acessibilidade para surdos, para contextualizar as linguagens cientificas. A partir disso, pesquisamos nos anais dos eventos ENPEC e SNEF para ficarmos cientes do que está sendo utilizado e como está sendo utilizado, e com esta pesquisa percebemos que pouquíssimos grupos estão utilizando de seu próprio aplicativo, o que pode trazer algumas limitações e improvisos. Nosso método foi identificar um problema, debater a melhor forma para resolvê-lo e então agir sem que tivéssemos que improvisar a frente de uma limitação (baseada em nossos planos) de um aplicativo de terceiros. Um dos diferenciais do nosso aplicativo é o método de ensino, que tem como objetivo, apresentar as diversas representações de um mesmo fenômeno. O aplicativo se mostra relevante para que esse estudante possa colocar diversas representações do mesmo fenômeno (ou modelo matemático) lado a lado, provocando-o a compreender suas vantagens e limitações. O aplicativo também está pronto para receber e trabalhar com outros conteúdos, podendo assim ter novas extensões, como Biologia, Química, Matemática, entre outros.
\end{abstract}

Palavras-Chave: Acessibilidade; Surdo; Aplicativo; Jogo-Digital; Ciência.

\section{Resumen}

El curso de Física presenta un alto índice de desistimiento en la Universidad Federal de Rio Grande - FURG, en especial en el primer año de ese curso. El problema se agrava aún más en lo que se refiere a las cuestiones de accesibilidad, implicando que acciones con prácticas inclusivas de las personas con discapacidad auditiva deben ser explotadas en las Universidades. Por eso, decidimos buscar otra estrategia, en ese caso, decidimos desarrollar un juego educativo con accesibilidad para sordos, para contextualizar los lenguajes científicos. A partir de eso, investigamos en los anales de los eventos ENPEC y SNEF para estar conscientes de lo que está siendo utilizado y como está siendo utilizado, y con esta investigación percibimos que poquísimos grupos están utilizando de su propia aplicación, lo que puede traer algunas limitaciones e improvisaciones. Nuestro método fue identificar un

\footnotetext{
${ }^{1}$ Graduando em Sistemas de Informação, FURG; Rio Grande; RS; Brasil, wesfarias.furg @gmail.com

${ }^{2}$ Doutorando no Programa de Pós-Graduação em Educação em Ciências; FURG; Rio Grande; RS; Brasil; willianrus@gmail.com

${ }^{3}$ Doutorado em Educação em Ciências pela Universidade Federal do Rio Grande, RS; Brasil; vamirheckler@furg.com
} 
problema, debatir la mejor manera para resolverlo y entonces actuar sin que tuviéramos que improvisar el frente de una limitación (basada en nuestros planes) de una aplicación de terceros. Uno de los diferenciales de nuestra aplicación es el método de enseñanza, que tiene como objetivo, presentar las diversas representaciones de un mismo fenómeno. La aplicación se muestra relevante para que ese estudiante pueda colocar diversas representaciones del mismo fenómeno (o modelo matemático) lado a lado, provocándolo a comprender sus ventajas y limitaciones. La aplicación también está lista para recibir y trabajar con otros contenidos, pudiendo así tener nuevas extensiones, como Biología, Química, Matemáticas, entre otros.

Palabras claves: Accesibilidad; Sordos; Aplicación; Digital-Juego; Ciência.

\begin{abstract}
The Physics course presents a high dropout rate at the Federal University of Rio Grande - FURG, especially in the first year of this course. The problem is further aggravated by accessibility issues, implying that actions with inclusive practices of people with hearing impairment should be explored in universities. Given this, we decided to pursue another strategy, in this case, we decided to develop an educational game with accessibility for the deaf, to contextualize the scientific languages. From this, we searched the annals of the ENPEC and SNEF events to be aware of what is being used and how it is being used, and with this research we realized that very few groups are using their own application, which can bring some limitations and improvisations. Our method was to identify a problem, to discuss the best way to solve it and then act without having to improvise ahead of a limitation (based on our plans) of a third-party application. One of the differentials of our application is the teaching method, which aims to present the various representations of the same phenomenon. The application proves relevant so that this student can put several representations of the same phenomenon (or mathematical model) side by side, causing him to understand its advantages and limitations. The application is also ready to receive and work with other content, and thus can have new extensions, such as Biology, Chemistry, Mathematics, among others.
\end{abstract}

Keywords: Accessibility; Deaf; Application; Digital-Game; Science.

\title{
1. Primeiros Passos
}

Vivenciamos um problema no curso de Física na Universidade Federal do Rio Grande (FURG), onde os alunos chegam motivados para o curso e, na maioria das vezes, dentro de um ano, já estão desistindo do mesmo. Acreditamos que um dos motivos dessa evasão é o fraco ensino médio, que não trabalha o conteúdo necessário para o aluno entender as linguagens da física. Visto isso, decidimos buscar outras estratégias, decidimos desenvolver um jogo educativo para contextualizar as linguagens cientificas.

Inicialmente, a proposta era desenvolver um quis no qual o estudante pudesse ver mais do que apenas a questão escrita. Que pudesse ver o máximo possível de linguagens que aquela única questão podia ter. Então começamos a pesquisar e, através de reuniões semanais, elaborar as questões e representações que dariam início ao jogo. Após alguns meses estruturando o projeto, inscrevemos o projeto em um edital para conseguirmos recursos para auxiliar no desenvolvimento do jogo. E durante a reunião desse edital, nos deparamos com o grupo (INFOEDUC) que apresentou outro grande problema na universidade, a evasão de alunos surdos. A partir disso, juntamos forças para tentarmos conseguir os recursos como um único projeto. Após sair o resultado do edital e nosso projeto não ganhar recursos, cada grupo 
voltou a seguir seu caminho sozinho, porém nosso grupo adotou o problema com acessibilidade e decidimos seguir em frente com a ideia de um jogo de ensino de física com acessibilidade para surdos.

Com o objetivo de criar um jogo de ensino de física com acessibilidade para surdos, nosso primeiro passo foi pesquisar nos anais dos eventos ENPEC e SNEF para ficarmos por dentro do que estava sendo utilizado e como estava sendo utilizado. Utilizamos as palavras “jogo", "surdez", "física” e "ciência” para filtrar nossas pesquisas. Encontramos diversos artigos interessantes nesse meio, principalmente direcionados a jogos de tabuleiro e similares, mas essa pesquisa também nos mostrou que pouquíssimos grupos estão trabalhando com desenvolvimento de seu próprio jogo digital educacional, e esse é um dos diferenciais desse projeto, pois tínhamos um problema e decidimos criar nossa própria solução, para que não nos deparássemos com problemas pois os aplicativos de terceiros poderiam não ter todas as funções que necessitávamos.

Consideramos o AcessaExata como um Quiz que se utiliza de diversas linguagens da ciência para auxiliar na construção de conhecimento por parte do usuário. $\mathrm{O}$ design do aplicativo inclui recursos típicos de jogos digitais como níveis, multiplayer e diversos modos de jogos diferentes. Neste sentido, discutimos brevemente o espaço do jogo digital no ensino e, logo em seguida, a fundamentação para o uso das múltiplas linguagens da ciência, em uma perspectiva semiótica, no ensino de Física.

\section{Fundamentação Teórica}

Os jogos digitais são costumeiramente mal-entendidos, visto como algo negativo seus elementos atrativos capazes de manter um jogador por horas diante da tela do jogo (PORTER, 2010). Contudo, essa característica de atração intrínseca aos jogos digitais também facilita a sua aplicação com finalidades educacionais, seja de aprendizagem, seja de conscientização e seja de socialização, como ocorre no caso dos jogos do gênero serious games, que são jogos de propósitos sérios com objetivos de conscientização para um problema social real (BREUER e BENTE, 2010). Esse processo de aprendizagem, presente em jogos digitais, nos abre possibilidades para a sua inclusão em currículos escolares ou na formação de profissionais de áreas específicas, a exemplo da docência. Griffiths (2002) descreve os benefícios educacionais dos jogos digitais, mostrando que os jogos digitais possuem um grande potencial positivo quando desenvolvidos para resolver problemas específicos ou para objetivos educacionais.

Outra vantagem da utilização de um jogo digital para o ensino, em especial o de 
Física, é a possibilidade de utilizar hypermídia no estudo das diferentes linguagens das Ciências. Significamos a linguagem, a partir de Santaella (1990), como os signos, aquilo que porta informação. Enquanto a linguística tem sua centralidade no estudar as linguagens verbais, escritas ou orais, a semiótica se preocupa com todos os tipos de linguagem, que vão incluir formas, movimento, interações, cores, sons, odores ou qualquer potencial portador de informação. Significamos esta linguagem científica como a linguagem especializada e/ou comum utilizadas de maneira especializada nos discursos de comunidades científicas (LEMKE, 1998). Ressaltamos que a mesma inclui palavras, imagens, tabelas, diagramas, gráficos, equações, símbolos, gestos ou qualquer outro signo. Lemke (1998) também significa a semiótica como um campo de estudo sobre como criar significado usando recursos culturais de um sistema de palavras, imagens, símbolos e ações. Neste sentido, as fotos, tabelas, gráficos, representações computacionais gráficas e vídeos são usados como linguagem dentro do aplicativo para compartilhar significados com o usuário.

Segundo Gilbert (2010), criamos representações para os fenômenos, necessárias tanto para compartilhar com outros membros quanto para nós mesmos significarmos esses modelos. Dentre essas, temos as representações internas, chamadas de visualizações, e as representações externas, que estão abertas a inspeção do outro. As maneiras genéricas com que podemos exteriorizar nossas visualizações incluem gestos, materiais concretos, visual, simbólico e verbal. Registramos ser importante estudar essas representações externas, que englobam tanto a escrita e a oralidade quanto as linguagens não verbais como imagens, materiais concretos, gráficos e tabelas que foram utilizados durante a disciplina, especialmente interligados à experimentação da lixeira. Neste sentido, Gilbert (2010) apresenta como representação visual os diagramas e visualizações gráficas. Diagramas são amplos em tipo, podendo variar desde fotos acrescentadas de linhas, setas, números e outras representações que venham a acrescentar informações até situações em que os objetos sejam representados apenas como símbolos em uma rede. Já as gráficas são capazes de apresentar grande quantidade de informações matemáticas de formas compactas como em tabelas e gráficos de diferentes tipos, apresentando informação visual de forma abstrata. O outro modelo de representação apresentado pelo autor é a simbólica. O referido autor inclui nesta categoria diversas representações que incluem, por exemplo, os elementos de uma tabela periódica, as unidades e as relações entre esses símbolos.

A partir dessas interlocuções, concluímos que o aprendizado dos conceitos centrais de um modelo explicativo passa pela compreensão das diferentes linguagens utilizadas pela comunidade que o sujeito se encontra. No caso do ensino de Física, apontamos a forte 
necessidade de lidar com a representação visual (diagramas e gráficos) e simbólica (unidades de símbolos) para compreender os fenômenos complexos estudados

Citamos três exemplos, a partir de, Evagorou et al. (2015) em que a representação visual é usada como objeto epistêmico: Como evidência - Quando a fotografia, ou imagem renderizada a partir de dados, é usada para corroborar um certo modelo, como nos casos da cristalografia do DNA e do desvio de luz do planeta Mercúrio; Aplicando o pensamento visual - Quando o avanço explicativo de um certo modelo acontecem pela analogia de fenômenos abstratos com recursos visuais, como nos casos das linhas do campo magnético de Faraday e dos experimentos mentais de Einstein e Bohr a respeito da mecânica quântica; na visualização dos métodos científicos - Quando a experimentação é documentada em fotos, vídeos, diagramas e outros, possibilitando divulgar as descobertas e metodologias. A exemplo, compreender melhor os protocolos de cada grupo e a diferença de protocolos entre grupos diferentes facilitam a comparação de resultados. Nos contextos anteriormente citados, procuramos o exemplo mais simples de um fenômeno, do que ele é composto, como interage com outros fenômenos e como essas características podem ser utilizadas para explicá-lo. Segundo Gilbert (2010), este é o processo de modelagem dentro das Ciências, sendo seu resultado um modelo. Interligado a este processo, criamos representações para os fenômenos, necessárias tanto para compartilhar com outros membros quanto para nós mesmos significarmos esses modelos. Dentre essas, temos as representações internas, chamadas de visualizações, e as representações externas, que estão abertas a inspeção do outro. Dito isto, ancoramos nesta concepção a aposta de proporcionar diferentes representações para a mesma situação com o objetivo de facilitar o entendimento dos modelos em questão. As diferentes perguntas, sendo estruturadas para o jogo digital, terão como pretensão explorar uma ou mais linguagens, sem privar o estudante de outras que ele já está familiarizado, e criando um contexto em que seja possível constituir traduções entre essas linguagens apresentadas.

\section{O AcessaExata}

O AcessaExata foi desenvolvido através da versão Personal da engine Unity 2018.2.11 e sua linguagem de programação é em C\#. Neste jogo, em formato de quis, os estudantes possuem acesso a uma série de perguntas, onde o objetivo é tentar respondê-las se apoiando em representações semióticas que incluem tabelas, gráficos, simulações visuais, diagramas e linguagem escrita. Registramos a centralidade nas diferentes representações, a nível de ensino médio, onde as diferentes perguntas conduzem o estudante por um ambiente propício para desenvolver conhecimento mais complexo dos modelos na medida que ele vai 
sendo apresentado em linguagens diferentes, e também constituindo assim um suporte para que os estudantes universitários possam reconhecer outras linguagens para os objetos matemáticos, fenômenos e modelos que eles estão estudando.

O aplicativo também conta com diversos modos de jogo, para que, além de tentar não deixar o estudo através do aplicativo se tornar enjoativo, o estudante também possa testar seus conhecimentos de diversas formas diferentes, fazendo com que seja mais fácil entender questões em diversas representações. Os modos de jogo presentes na primeira versão do aplicativo são:

- Modo Aprendizado: é o modo onde os estudantes escolhem um determinado tema, no qual possui uma série de perguntas de múltipla escolha e pode-se utilizar ilimitadamente as representações semióticas de cada uma das questões, além de apresentar a correção de cada questão;

- Modo Corrida Contra o Tempo: é o modo onde os estudantes precisam responder as questões antes que o tempo acabe, contando também com a ajuda das representações;

- Modo Carreira: é o modo onde os estudantes ganharão estrelas pelo desempenho de cada nível jogado, e essas estrelas serão necessárias para desbloquear novos níveis. Este modo conta com diversos temas e desafios diferentes, como, por exemplo, escolher a alternativa que melhor descreve um gráfico;

- Modo Competitivo: é o modo onde os estudantes poderão desafiar os amigos em uma partida compartilhada e personalizada.

Além disso, objetiva-se implementar um modo para que se possa adicionar questões e controlar uma "sala online". Um exemplo seria um professor criar uma sala de estudos, utilizando o AcessaExata em um laboratório de informática, com questões específicas para que seus alunos estudem o conteúdo de uma prova de maneira mais descontraída. Também objetiva-se criar um fórum online voltado para a discussão das perguntas pela comunidade de usuários e responsáveis pelo aplicativo.

Um dos grandes diferenciais do AcessaExata está na proposta para inclusão de Surdos, e a acessibilidade, do aplicativo, foi desenvolvida com muito cuidado e atenção. Cada processo foi realizado com o auxílio e opinião de professores surdos, interpretes de LIBRAS e alunos surdos da FURG. Um exemplo é o início, onde iriamos utilizar um personagem 
animado para interpretar os textos do aplicativo (como mostra a figura 1), mas após algumas revisões com professores e alunos surdos, descobrimos que há certa dificuldade em interpretar personagens animados e se sentem muito mais à vontade com um interprete real em vídeo. Também tomamos o cuidado de utilizarmos ícones que remetam o significado de qualquer texto utilizado.
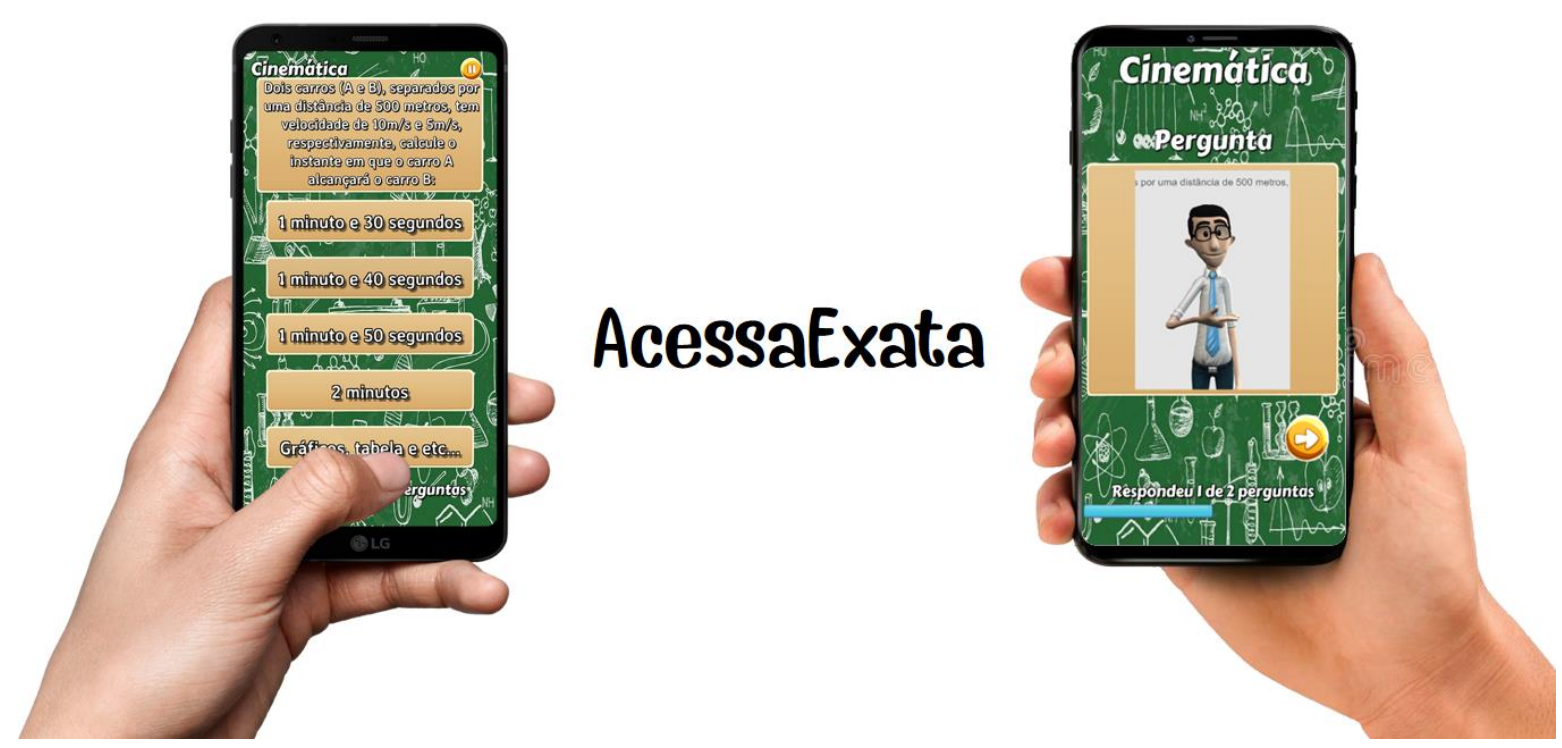

Figura 1 - Uma mesma questão vista em línguas diferentes.

Fonte: própria.

O AcessaExata também traz algumas configurações pessoais para deixar o aplicativo mais agradável (como mostra a figura 2). Também objetiva-se adicionar um personagem que possa ser personalizado através de conquistas no Modo Carreira, para que o estudante se sinta mais motivado a estudar através do aplicativo buscando melhorar seu personagem e automaticamente seus conhecimentos. 




Figura 1 - Dois designs diferentes que podem ser utilizados no aplicativo.

Fonte: própria.

O AcessaExata primeiramente será disponibilizado somente para smartphones android, mas um dos próximos passos é disponibiliza-lo para as plataformas Linux, Windows, iOS e Web. Por último, pretendemos integrar o software ao AVA Moodle, na forma de API, para uso nas disciplinas presenciais e à distância. O AcessaExata estará disponível para download em: https://ciefi.furg.br/repositorio.

\section{Referências}

BREUER, J.; BENTE, Gary. Why so serious? On the relation of serious games and leraning. Eludamos. Journal for Computer Game Culture, v. 4, n. 1, p. 7-24, 2010.

EVAGOROU, M. The role of visual representations in scientific practices: from conceptual understanding and knowledge generation to 'seeing' how Science Works. International Journal of STEM Education, Setembro, 2015. Disponível em: https://stemeducationjournal.springeropen.com/articles/10.1186/s40594-015-0024-X. Acesso em: 11 ago. 2018.

GILBERT, J. K. The role of visual representations in the learning and teaching of Science: An introductin Asia-Pacific Forum on Science Learning and Teaching, v. 11, n. 1. 2010.

GRIFFITHS, M. D. The educational benefits of videogames. Education and Health. Exeter: SHEU. V. 20, n. 3, p. 47-51. 2002. 
LEMKE, J. L. Teaching all the languages of Science: words, symbols, images and actions. Conference on Science Education, 1998, Barcelona. Disponível em: http://academic.brooklyn.cuny.edu/education/jlemke/papers/barcelon.htm. Acesso em 21 dez. 2018. 